\title{
Blade Tip Pressure Measurements using Pressure Sensitive Paint
}

\author{
Oliver D. Wong \\ oliver.d.wong@nasa.gov \\ US Army Aeroflightdynamics Directorate, Joint Research Program Office \\ Hampton, VA \\ A. Neal Watkins \\ anthony.n.watkins@nasa.gov \\ Advanced Sensing \& Optical Measurement Branch, NASA Langley Research Center \\ Hampton, VA \\ Kyle Z. Goodman \\ $\frac{\text { kyle.z.goodman@nasa.gov }}{\text { ATK }}$ \\ ATK \\ Hampton, Virginia

$\begin{array}{ccc}\text { Jim Crafton } & \text { Alan Forlines } & \text { Larry Goss } \\ \text { jwcrafton@innssi.com } & \text { alan.forlines@innssi.com } \\ & \begin{array}{c}\text { Innovative Scientific Solutions, Inc. } \\ \text { Dayton, Ohio }\end{array} & \end{array}$

James W. Gregory
gregory.234@osu.edu
The Ohio State University
Columbus, Ohio

\section{ABSTRACT}

This paper discusses the application of pressure sensitive paint using laser-based excitation for measurement of the upper surface pressure distribution on the tips of rotor blades in hover and simulated forward flight. The testing was conducted in the Rotor Test Cell and the 14- by 22-ft Subsonic Tunnel at the NASA Langley Research Center on the General Rotor Model System (GRMS) test stand. The Mach-scaled rotor contained three chordwise rows of dynamic pressure transducers for comparison with PSP measurements. The rotor had an $11 \mathrm{ft} 1 \mathrm{in}$. diameter, $5.45 \mathrm{in}$. main chord and a swept, tapered tip. Three thrust conditions were examined in hover, $\mathrm{C}_{\mathrm{T}}=0.004,0.006$ and 0.008 . In forward flight, an additional thrust condition, $\mathrm{C}_{\mathrm{T}}=0.010$ was also examined. All four thrust conditions in forward flight were conducted at an advance ratio of 0.35 .

\section{NOTATION}

$14 \times 22$ - NASA LaRC 14- by 22-Foot Subsonic Tunnel

ABS - Advancing blade side

c - Chord length (in.)

CCD - Charged-Coupled Device

$\mathrm{C}_{\mathrm{T}} \quad-\quad$ Rotor thrust coefficient, $\frac{T}{\pi R^{2} \rho(\Omega R)^{2}}$

D - - Rotor diameter (ft)

FIB - A PSP binder, fluoro-isopropyl-butyl

GRMS - General Rotor Model System

$\mathrm{h} \quad$ - Rotor/ground separation distance (ft)

$\frac{h}{D} \quad$ - Non-dimensional rotor/ground plane separation

LED - Light Emitting Diode

$\mathrm{M}_{\text {Tip, } \psi} \quad$ - $\quad$ Tip Mach number at $\psi$

PIV - Particle Image Velocimetry

Presented at the American Helicopter Society 68 ${ }^{\text {th }}$ Annual Forum, Fort Worth, Texas, May 1-3, 2012. This is a work of the U.S. Government and is not subject to copyright protection in the U.S.

$\begin{array}{lll}\text { PSP } & - & \text { Pressure Sensitive Paint } \\ \text { Pt(TfPP)- } & \begin{array}{l}\text { A PSP luminophore, Platinum meso- } \\ \text { tetra(pentafluorophenyl)porphine }\end{array} \\ \text { R } & - & \text { Blade radius (ft) } \\ \text { RBS } & - & \text { Retreating blade side } \\ \text { RASP } & - & \text { Rotor Azimuth Synchronization Program } \\ \text { ROBIN } & \text { - } & \text { ROtor Body Interaction } \\ \text { Ru(dpp) - } & \text { A PSP luminophore, Ruthenium } \\ \text { RTC } & - & \text { bathophenanthroline } \\ \text { T } & \text { Rotor Test Cell } \\ \text { TSP } & \text { - } & \text { Rotor thrust (lb) } \\ \text { V } & \text { Temperature sensitive paint } \\ \frac{x}{c} & \text { - } & \text { Tunnel velocity }\left(\frac{f t}{s}\right) \\ \alpha_{\text {Shaft }} & - & \text { Non-dimensional chord length } \\ \end{array}$




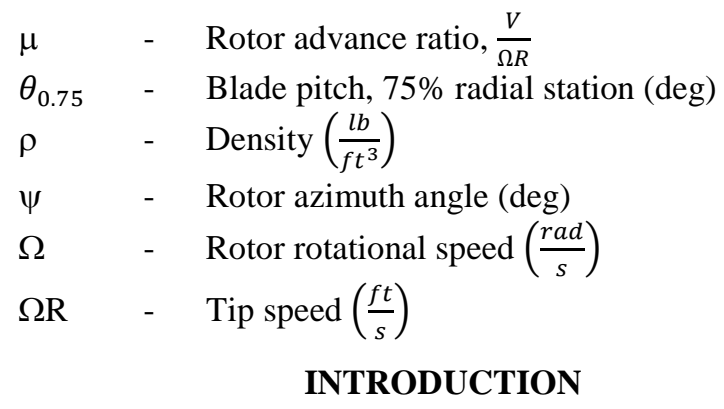

In order to advance analytical prediction methods used for rotorcraft aerodynamics, acoustics, and interactional effects, it is vital that the fundamental physics of the rotor blade tip flow be better understood. One way to achieve this is to examine the pressure distribution at the blade tip. There has been considerable research involving pressure measurements on rotor blades ${ }^{1-2}$. These measurements, however, typically lack the resolution to capture phenomena such as the nascent tip vortex or dynamic stall. Instrumenting the blades with additional transducers to increase spatial resolution can quickly become prohibitive due to the cost and practicality of fitting a large number of sensors into a small area. The added centrifugal loads of the pressure transducers can rapidly become unmanageable. Pressure sensitive paint (PSP) can potentially overcome the limitations of existing measurement techniques. PSP can offer a significant increase in spatial resolution and a potential cost savings over discrete transducers. Static PSP measurement techniques have matured to the point where they can be used for fixed wing measurements in large scale production wind tunnel environments. Dynamic PSP measurement techniques have recently become available. Much research has focused on using dynamic PSP on turbo machinery. Dynamic PSP may enable high resolution pressure measurements on helicopter rotors, thus allowing more accurate analytical prediction methods. Work in this area has been very limited to date ${ }^{3-7}$. Over the last several years, the US Army Aeroflightdynamics Directorate, Joint Research Program Office and the NASA Subsonic Rotary Wing Project have partnered to develop PSP measurement techniques for use on rotor blades. To date this work has focused on Mach-scaled model rotors in hover and in simulated forward flight in the 14- by 22-Foot Subsonic Tunnel at the NASA Langley Research Center. Previous work by this partnership includes initial proof of concept work in 2003 and more refined hover testing using pressure instrumented blades in 2008. This paper describes measurements of blade upper surface pressure using a laserbased, single-shot PSP technique on a model scale rotor in both hover and forward flight.

\section{PSP Primer}

The PSP technique exploits the oxygen $\left(\mathrm{O}_{2}\right)$ sensitivity of luminescent probe molecules suspended in gas-permeable binder materials. If the test surface under study is immersed in an atmosphere containing $\mathrm{O}_{2}$ (e.g. air), the recovered luminescence intensity can be used to determine pressure (P) via a modified form of the Stern-Volmer relationship

$$
\left(\frac{I_{\text {re f }}}{I}\right)=A(T)+B(T)\left(\frac{P}{P_{\text {Re f }}}\right)
$$

where I is the luminescence intensity at some partial pressure of oxygen, $\mathrm{I}_{\mathrm{REF}}$ is the recovered luminescence intensity at a reference pressure, $\mathrm{P}_{\mathrm{REF}}$. The coefficients $\mathrm{A}(\mathrm{T})$ and $\mathrm{B}(\mathrm{T})$ are temperature dependent constants for a given PSP formulation and are usually determined beforehand using laboratory calibration procedures.

There are two methods for acquiring PSP data: intensity-based and lifetime-based. The authors' previous testing has shown that the lifetime-based approach is required to deal with the aeroelastic deformation of the rotor blades $^{6}$. As such, only the lifetime-based technique will be described here. In the lifetime-based technique, excitation of the PSP is accomplished using a modulated light source (e.g. a laser, flash lamp, or pulsed LED arrays). A fast framing camera (intensified CCD or interline transfer CCD) is used to collect the excited state luminescence decay. Typically the decay is approximated by acquiring two or more images at different delay times during and/or after the pulsed excitation and integrating photons for fixed periods of time (i.e. gate widths) that have been predetermined to maximize the pressure sensitivity, as demonstrated in Figure 1. The first image, Gate 1, usually consists of a short gate width and is collected either during the excitation pulse or shortly after it ends. This can be thought of as the reference image because the excited-state decay has the least pressure sensitivity. The second image, Gate 2, is taken at a later time after the excitation pulse and usually has a longer gate width, ensuring maximum pressure sensitivity. These images, in conjunction with a modified Stern-Volmer approach (Eq. 1), can then be used to determine surface pressure.

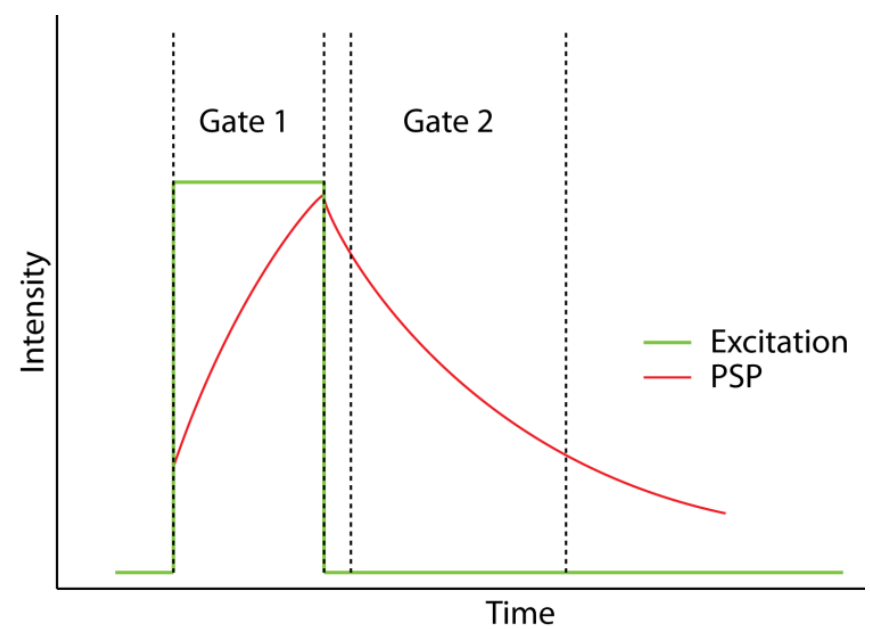

Fig. 1- Schematic representation of lifetime-based data acquisition showing excitation (green) and measured 
emission (red). The gate regions represent example Gate 1 (during excitation) and Gate 2 (after excitation).

PSP is fundamentally a low light technique. The emission from the paint is extremely low. Due to this characteristic, it can be challenging to obtain a reasonable signal-to-noise ratio. The standard operating procedure is to run all measurements in the dark. Additionally, background images are collected and subtracted from the data images to remove any remaining ambient light and compensate for camera noise. In the previous work by Wong, et al. ${ }^{6,7}$, the data images were "built up" from hundreds of exposures (rotor revolutions). For this method to work, the PSP must be excited by the same illumination field for each revolution. If the illumination field is not identical for each revolution, the non-uniformities will be manifested as apparent pressure changes. Large LED arrays are frequently used for excitation since they have very stable pulse-to-pulse characteristics.

In the past, even though pulsed lasers are much brighter excitation sources, they have not been typically used for PSP since they exhibit non-uniform pulse-to-pulse illumination fields. Due to existing camera technology at the time, it had been necessary to capture Gate 1 and Gate 2 images using different laser pulses. With a different illumination field during each image, it was not possible to differentiate between intensity changes due to pressure changes or excitation illumination field changes. By utilizing interline transfer cameras developed for PIV, it is now possible to capture the Gate 1 and Gate 2 images from the same laser pulse. The pulse-to-pulse illumination non-uniformity is accounted for when the images are ratioed. As a result, it is now practical to utilize pulsed lasers for PSP measurements. Since both images are captured with a single pulse, the laser - based method should alleviate the smear associated with the rotation-to-rotation blade position variation.

\section{EXPERIMENTAL SETUP}

\section{Rotor Hardware}

The GRMS and modified ROtor Body Interaction (ROBIN) fuselage were used for these tests. GRMS is a generic rotor drive system that allows testing of different rotor and fuselage configurations. GRMS is powered by two, $75 \mathrm{hp}$, water-cooled electric motors that drive a 5.47:1 transmission. Two six-component strain gage force and moment balances are contained within GRMS to enable separate measurement of rotor and fuselage loads. The rotor hub is a four-bladed fully articulated hub. One blade cuff is instrumented to measure cuff pitch, lead-lag and flapping. Additional instrumentation on GRMS includes an encoder to provide $1 / \mathrm{rev}$ and 1024/rev timing signals and accelerometers to monitor machine health. A slipring containing 90 circuits mounted to the bottom of the rotor shaft was used to transfer the signals from the hub and blade mounted instrumentation to the stationary frame. For a more complete description of the GRMS see ref. 8.
The fuselage is similar to the original ROBIN fuselage 9 with the exception of a rear ramp section. The ROBIN fuselage is an analytically defined representative generic helicopter fuselage that has been used in much previous work. The modified ROBIN fuselage used in these tests uses the same family of super-ellipse equations as the original ROBIN fuselage while using a modified set of coefficients to generate the ramp section ${ }^{10}$. The modified ROBIN has nominal +3 degree nose up pitch relative to the GRMS rotor shaft.

The $11.08 \mathrm{ft}$ diameter rotor uses RC-series airfoils ${ }^{11-12}$. Two of the four blades were instrumented with dynamic pressure transducers measuring the upper surface pressure distributions. One blade contained two chordwise rows of ten transducers located at $93 \%$ and $99 \%$ of the rotor radius. The second pressure-instrumented blade contained a single row of ten transducers at $93 \%$ of the rotor radius. The blade containing the two rows of pressure transducers was also instrumented with strain gages to measure the flap-wise, chord-wise and torsional bending moments for safety of flight purposes. The blade planform, airfoil distribution and instrumentation location are shown in Figure 2. Rotor characteristics are listed in Table 1.

In order to stay within allowable loads, the rotor pilot trims the $1 /$ rev flapping to zero. The pilots are capable of maintaining zero flapping within $\pm 0.25^{\circ}$.

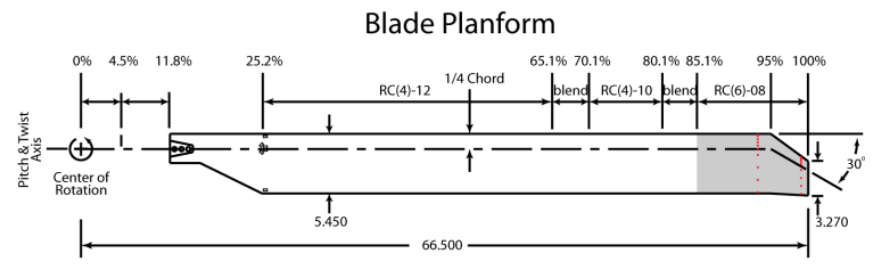

Instrumentation Locations

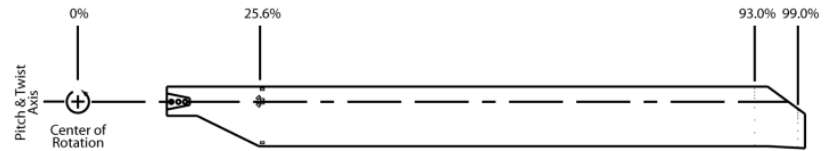

Fig. 2 - PSP rotor planform, airfoil distribution and instrumentation location. All dimensional units in inches unless marked.

\begin{tabular}{|l|l|}
\hline Rotational Speed (rpm) & 1150 \\
\hline Number of Blades & 4 \\
\hline Blade Chord (ft) & 0.4542 \\
\hline Rotor Radius (ft) & 5.5417 \\
\hline Rotor Airfoil & RC series \\
\hline Blade Twist Distribution & Linear \\
\hline Blade Twist (deg) & -14 \\
\hline Tip Speed (ft/s) & 666 \\
\hline Hover Tip Mach Number & 0.58 \\
\hline Rotor Area Solidity $(\sigma)$ & .1033 \\
\hline
\end{tabular}

Table 1 - PSP Rotor Properties 


\section{Test Facilities}

All testing was conducted either in the rotor test cell (RTC) or in the 14- by 22-Foot Subsonic Tunnel $(14 \times 22)$ at NASA Langley Research Center in Hampton, VA. Both of these facilities are located in the $14 \times 22$ Complex. The RTC is a highbay area $68 \mathrm{ft}$ long, $40 \mathrm{ft}$ wide and $43 \mathrm{ft}$ tall. Louvers at the top and bottom of the west and half of the north wall reduce recirculation in the RTC. A chain link fence at the perimeter of the room contains debris in the event of a model failure. The RTC is frequently used to support model build-up operations for wind tunnel tests, but can also be used as a stand-alone facility for hover testing.

GRMS was mounted to a long sting which in turn was mounted to one of the facility model carts. The model cart has both pitch and elevation control enabling the model to be trimmed to zero $\alpha_{\text {Shaft }}$ and constant height. The hover PSP measurements were made in conjunction with downwash/outwash measurements. In order to represent the ground plane, a second model cart was placed under the rotor. The RTC configuration is illustrated in Figure 3.

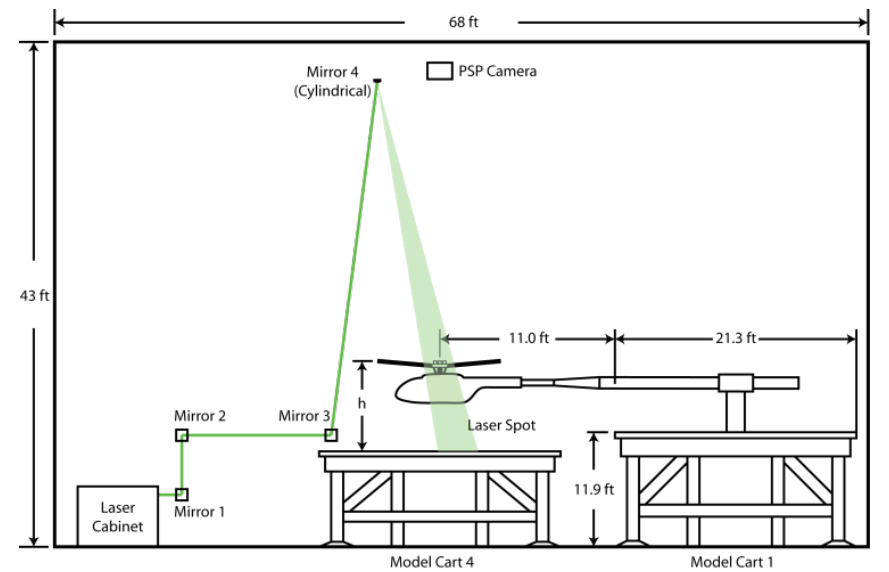

Fig. 3 - Hover configuration in the Rotor Test Cell

The forward flight portion of the testing was conducted in the $14 \times 22$. The $14 \times 22$ is an atmospheric, closed return tunnel with a test section $14.5 \mathrm{ft}$ high, $21.75 \mathrm{ft}$ wide, and 50 $\mathrm{ft}$ long. The tunnel can reach a maximum forward velocity of $348 \mathrm{ft} / \mathrm{sec}$ with a dynamic pressure of 144 psf. The Reynolds number per foot ranges from 0 to $2.2 \times 10^{6}$. Test section airflow is produced by a $40 \mathrm{ft}$ diameter, 9-bladed fan driven by a 12,000 hp main drive. For a more complete description of the $14 \times 22$ see ref. 13 .

The model configuration for the wind tunnel test was similar to the hover configuration. The only differences were a shorted sting to minimize the sting length aft of the model cart mast head. The other change was to mount the sting to Model Cart 7, which is shorter than Model Cart 1. This enabled the configuration to be moved into the tunnel from the RTC without disassembly, drastically shortening the required initial wind tunnel checkout time. The wind tunnel configuration is shown in Figure 4.

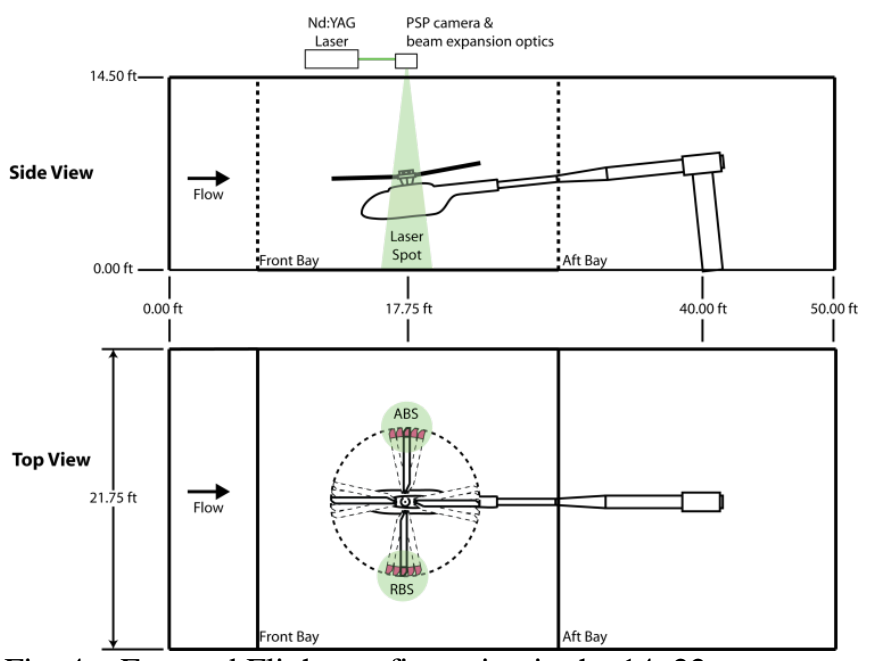

Fig. 4 - Forward Flight configuration in the $14 \times 22$

\section{Pressure Sensitive Paint Setup}

The camera for the hover measurements was located in a housing mounted to the ceiling of the RTC. The housing was positioned above and just outside of the rotor disc at an azimuth of $270^{\circ}$. A frequency-doubled Nd:YAG laser (532nm) was used as the PSP excitation source. A series of mirrors was used to direct the beam from the laser on the RTC floor to a spherical mirror mounted to the ceiling. The spherical mirror expanded the beam and directed it toward the measurement region. The diameter of the beam at the rotor disc was approximately $3 \mathrm{ft}$. An optics package and a diffuser immediately following the spherical mirror were used to expand and diffuse the beam to provide the required spot size. The location of these components is illustrated in Figure 3.

For the wind tunnel, two identical acquisition packages were developed. Each package contained a frequency-double Nd:YAG laser, conditioning optics and a camera. The packages were located on the test section ceiling, above windows that allow visual access to the advancing and retreating blade sides of the rotor.

In both cases, the images were captured using a cooled interline transfer CCD camera operating in a dual frame mode. The camera operates by masking every other line of the chip, allowing for charge to be transferred quickly ( 200 ns transfer time) from the unmasked region to the masked region for either storage or readout. The active area of the CCD chip is $1600 \times 1200$ pixels and the digitizer operates at 14-bit resolution. The dual frame mode allows for the acquisition of an image followed nearly instantaneously (after the 200 ns interline transfer time) by the acquisition of 
another image. The paint was excited with a 5 ns duration laser light pulse. The first image (Gate 1) was collected so that the laser flash occurred at the end of the exposure (within $1 \mu \mathrm{s}$ ) and the second image (Gate 2) of the dual frame encompassed the majority of the excited state decay (Figure 5). Thus, both images (Gate 1 and 2) were acquired using only a single pulse of the laser, alleviating such issues as flash-to-flash stability and laser speckle. To increase collection efficiency, the CCD chip was binned horizontally and vertically by 2 (effective imaging area of 800x600 pixels).

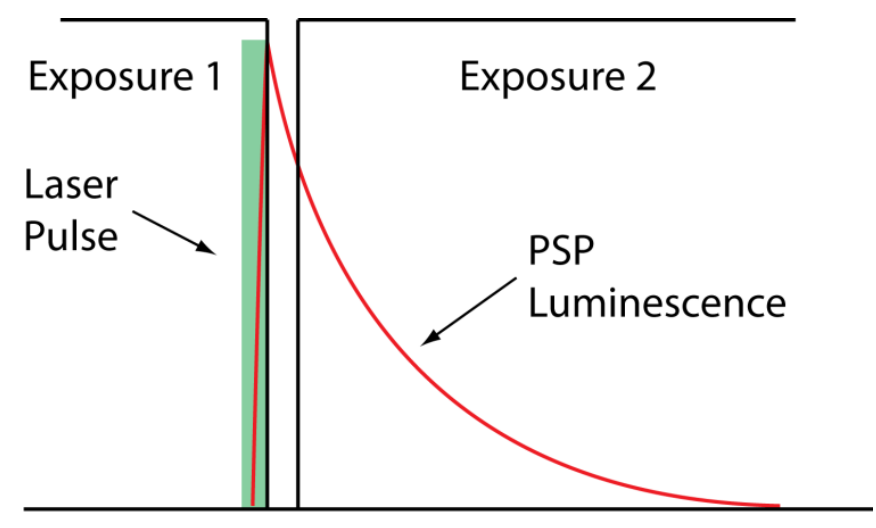

Time

Fig. 5 - Schematic representation of data acquisition using dual frame imaging and laser pulse excitation. Laser pulse width and delay between images is exaggerated to show difference.

The rotor azimuth synchronization program (RASP) system enabled the PSP system to be synchronized reliably with rotor azimuth. RASP is a hardware and software rotor synchronization system developed by the NASA Subsonic Rotary Wing Project ${ }^{14}$. It utilizes the $1 /$ rev and $1024 / \mathrm{rev}$ from the rotor shaft encoder to generate azimuth locked timing pulses. The RASP and a programmable delay box were used to synchronize the cameras and laser flash lamps and Q-switches to the rotor.

During the hover portion of the test, there was no direct synchronization between the PSP system and the dynamic data acquisition system. Data collection for both systems was started at the same time, but there was no way to directly correlate the PSP collection with the dynamic data collected from the blade pressure transducers. For the forward flight test, an additional signal line was used to send the PSP camera timing pulses to the dynamic data acquisition system. This enabled the PSP data to be directly correlated with the dynamic blade pressure data.

Several paint formulations were assessed. In the hover testing, three blades were painted with different PSP formulations to determine which was most suitable for the forward flight entry. The three formulations consisted of a luminescent probe, Pt(TfPP), immobilized in either a FIB copolymer, a porous polymer ${ }^{15-16}$, or $\mathrm{Ru}(\mathrm{dpp})$ in $\mathrm{RTV}^{17}$. In each case, only the outer $15 \%$ of the blade was painted with PSP. The fourth blade was painted with temperature sensitive paint $(\mathrm{TSP})^{17}$.

Based on the experience gained in the hover test in regards to durability and ease of application, the porous polymer was selected for the forward flight test. Two blades were coated with the porous polymer formulations for forward flight. This binder can routinely measure dynamic pressure fluctuations at $5 \mathrm{kHz}$ and has been demonstrated to potentially measure fluctuations up to $20 \mathrm{kHz}{ }^{18}$.

In preparation for hover testing, each pressure transducer was masked using approximately 0.060 in. diameter masking tape dots to prevent the orifices from becoming clogged during the painting process. After painting, the dots were removed. A circular discontinuity was noticeable surrounding each pressure transducer office. This was the result of paint buildup from the blades being repainted several times over the course of the PSP measurement development effort. Before the forward flight entry, the PSP and primer coats were stripped to remove the discontinuity. A strip of tape approximately 0.10 in. wide was used to mask the entire row of taps. A slight discontinuity on either side of the pressure transducer rows existed, however there were no discontinuities in the chordwise direction.

\section{DATA REDUCTION}

As previously mentioned, the lifetime-based data acquisition process must be used to in order to effectively deal with the aeroelastic motion of the blade. Lifetime-based data analysis is usually conducted by dividing Gate 1 by Gate 2 to form the $\mathrm{I}_{\mathrm{REF}} / \mathrm{I}_{\text {Image }}$ ratio. However, the porous polymer displays a significant change in performance that is tied to the application process. This phenomenon has been observed previously in many PSP formulations ${ }^{19-20}$ but is very pronounced in this formulation. Essentially, the excited state lifetime of the $\operatorname{Pt}(\mathrm{TfPP})$ shows heterogeneity with application, where the lifetime can change dramatically based on the relative localized concentration of the probe. To solve this, a single wind-off image set was acquired immediately after the overspray. Since the overspray was done each morning, this wind-off image set was also acquired each morning. The wind-off image pair served as a further reference for the lifetime data and can correct for much of the non-homogeneity effects. The basic data analysis utilized the following protocol:

\section{Background correction of all images}

2. Registration of wind-on images Gate 1 and Gate 2 to the Gate 2 image of the wind-off pair 
3. Creating a "ratio of ratios" image using the wind-off image pair

4. Mapping the resultant image to the surface grid using the previously determined three dimensional coordinates of registration marks added to the blade

5. Final calibration of the image to convert to pressure. The calibration used in this work is known as an a priori calibration, which uses both temperature and pressure measurements made in a laboratory setting to convert from intensity to pressure.

\section{RESULTS \& DISCUSSION}

\section{LED vs Laser-Based PSP}

A comparison between the Gate 1 images from the LED and the laser-based excitation methods is shown in Figures $6 \mathrm{a}$ and $6 \mathrm{~b}$, respectively. Figure $6 \mathrm{a}$ is from previous work described in Ref. 7. It is the result of approximately 750 LED pulses (rotor revolutions). The edges of the blade and the black dots that serve as registration marks for mapping the data onto a surface grid are not sharp. The blur is due to the averaging as a result of blade position variations from revolution to revolution. Figure $6 \mathrm{~b}$ shows the Gate 1 image from a single laser pulse. The edges of the blade and the registration marks are much sharper than in LED excitation case. It should be noted however, that even with the short laser pulse, the motion of the blade is not completely frozen. There is still noticeable blur near the tip where the linear velocity is highest.

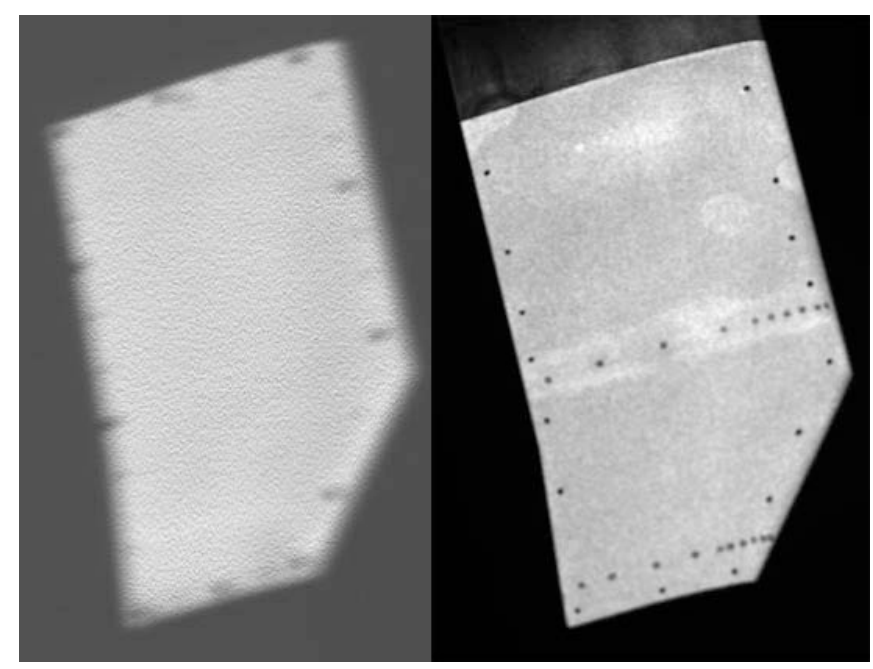

(a)

(b)

Fig. 6 - Gate 1 comparison between (a) LED excitation built from approximately 750 revolutions. Note image blur due to revolution-to-revolution blade position variation, (b) laser excitation - single revolution.

While the Gate 1 image exposure is fixed by the nanosecond duration laser pulse, the Gate 2 image is the result of a much longer exposure. The camera exposure is as long as it takes to read out the Gate 1 image, in this case 0.4 seconds. Due to running the experiment in the dark, the Gate 2 exposure is effectively fixed by the length of the luminophore decay. In this, case, the lifetime of the Pt(TfPP) used in this test is approximately $10 \mu \mathrm{sec}$. Over the $10 \mu \mathrm{sec}$ that the paint is emitting light, the blade tip, with a Vtip = $667 \mathrm{ft} / \mathrm{s}$, travels 0.080 inches. This is large enough to blur the Gate 2 image (Figure 7)

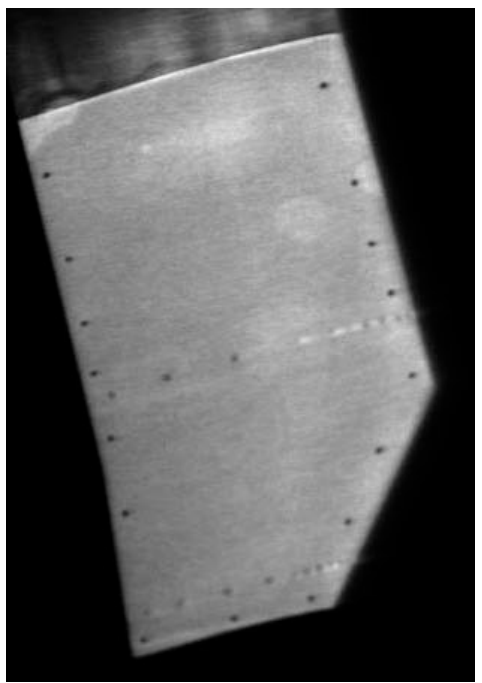

Fig. 7 - Laser-based technique Gate 2 image. Note the blurring at the blade perimeter and registration marks indicating blade motion during exposure

The final difference between the laser- and LED-based PSP techniques is the significant increase in the range between black and white values in Figure 6b, when compared Figure 6a. This indicates a much improved signalto-noise ratio. This signal-to-noise ratio enables pressure measurement with an image pair from a single laser shot; a vast improvement over the $750+$ pulse required with the LED-based technique.

\section{Wind-Off Gate 1 and Gate 2 Ratios}

Wind-off image pairs were collected during both the hover and forward flight portions of the test. These wind-off images form the ratio used in the data reduction process, to compensate for PSP application process intensity variations. In these images, it was noted in the hover case that there were large blotch-like intensity differences in the vicinity of the masked pressure transducers. These blotches were not observed in the wind-on images, suggesting that the blotches are the result of the luminophore doping process used at the beginning of each test day. The procedure was to spray a mixture of a solvent, methyl ethyl ketone, and lumiophore, Pt(TfPP), on the blade tips. The solvent would then evaporate, leaving the luminophore behind. At that point, the wind-off images were collected. Since the blotches did not show up in the wind-on data images, it is hypothesized that the solvent may not have fully evaporated before the wind- 
off images were collected. In hover, there do not appear to be any significant application variations. Because of this, the use of wind-off images for application compensation was not required. In forward flight, small blotches were noted in the wind-off images. They tended to be small, however, and were judged to be correctible through patching with data cloned from adjacent areas. Application variations were noted in the forward flight data. Thus in forward flight, the wind-off images were used to correct for these.

\section{Hover}

In hover, the PSP measurements were made at an $\alpha_{\text {Shaft }}$ of 0.0 degrees and an $\mathrm{h} / \mathrm{D}=0.9$. Three thrust conditions were examined, $\mathrm{C}_{\mathrm{T}}=0.004,0.006$ and 0.008 .

Figure 8 shows the blade tip surface pressure distribution at three thrust conditions. The inboard region that is black does not contain PSP data. The artifacts from the unpainted regions surrounding the pressure transducer orifices are the low indicated pressure regions at the $93 \% \mathrm{R}$ and $99 \% \mathrm{R}$ stations on the blade. They are circled for clarity. At the trailing edge of the blade there is a high pressure region that increases in width $(\mathrm{x} / \mathrm{c})$ as a function of blade radius. This region remains constant for all thrust conditions. Due to these behaviors, it is believed that this is an edge effect as a result of the blur in the Gate 2 image.

The lowest $\mathrm{C}_{\mathrm{T}}, 0.004$, is shown in Figure 8a. A broad low pressure region is observed across the leading edge of the blade. In the chordwise direction the pressure gradually recovers over the airfoil, increasing as it reaches the trailing edge. At the next thrust condition, 0.006, a suction peak has formed and is clearly visible along the leading edge. At approximately the $96 \%$ radial station, the suction peak starts to weaken as radius increases. Just inboard of the tip a weak low pressure region has formed. It is a chordwise line slanting inboard towards the trailing edge. In Figure 8c, the suction peak has increased in strength and now covers the entire leading edge. There appears to be a weakening of the suction peak in the last $0.5 \%$ of the blade radius. The low pressure region at the tip, as observed at the previous condition, has increased in strength and appears as a low pressure line connecting the two aft registration marks on the tip. It is believed that the low pressure region at the blade tip is the result of the tip vortex.

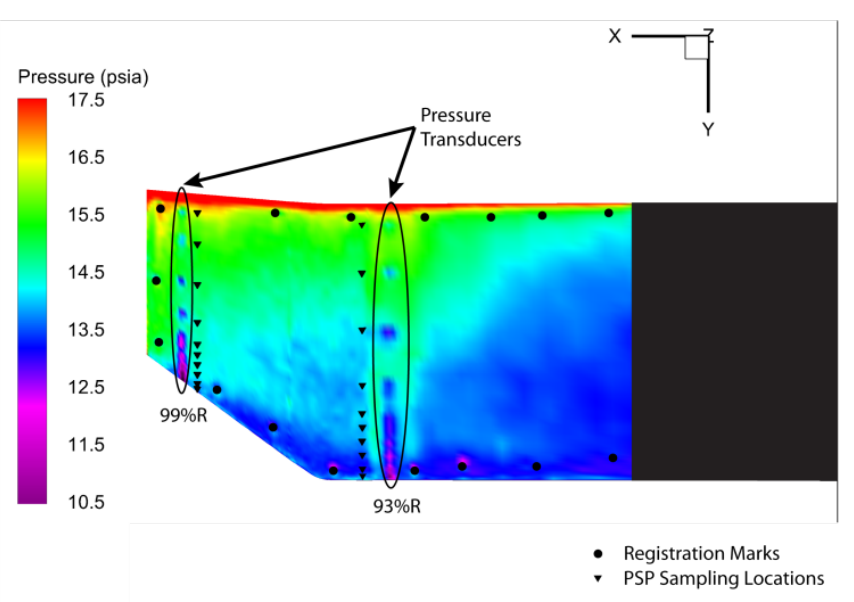

(a) $\mathrm{C}_{\mathrm{T}}=0.004$

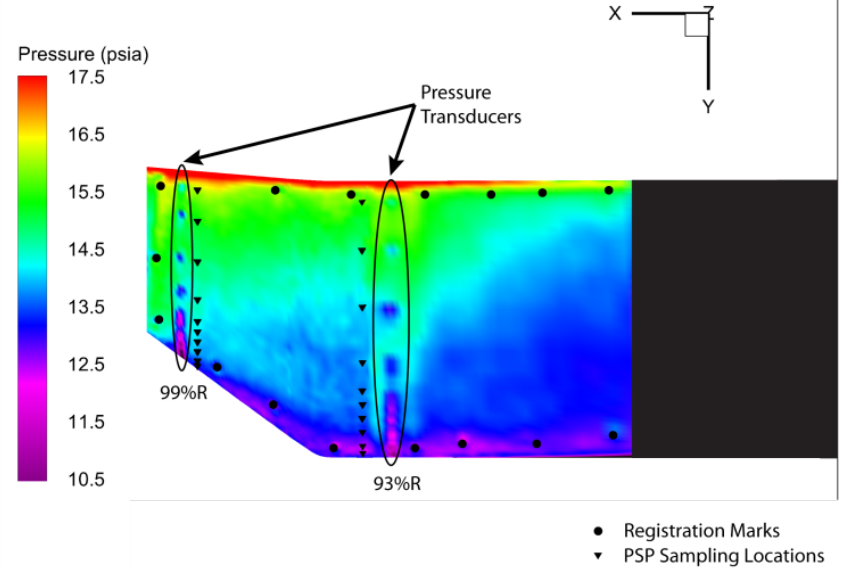

(b) $\mathrm{C}_{\mathrm{T}}=0.006$

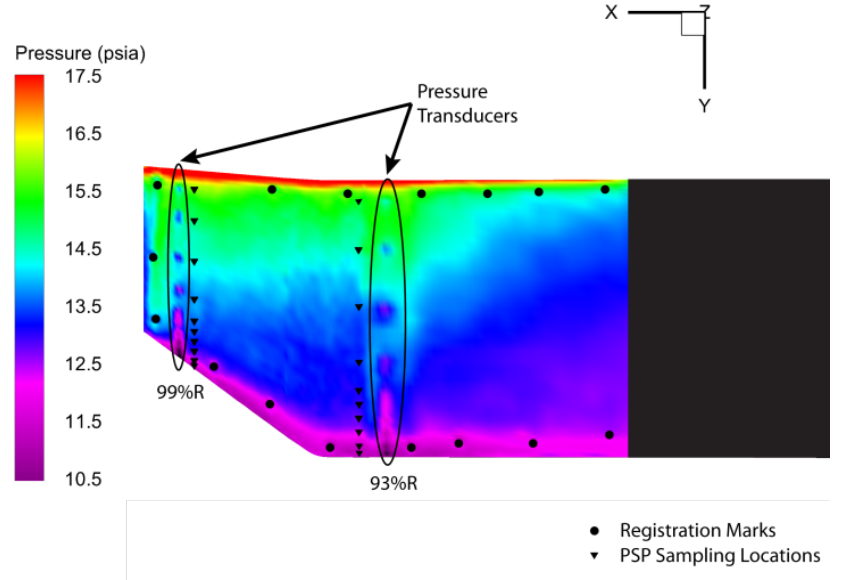

(c) $\mathrm{C}_{\mathrm{T}}=0.008$

Fig. 8 - Blade surface pressure distribution in hover. (a) $\mathrm{C}_{\mathrm{T}}$ $=0.004$, (b) $\mathrm{C}_{\mathrm{T}}=0.006$ and (c) $\mathrm{C}_{\mathrm{T}}=0.008$, MTip Hover $=$ 0.58 .

Comparisons between the PSP and the available pressure taps are shown in Figure 9. Due to the artifacts in the PSP at the pressure tap locations, the PSP data for the comparison was extracted along the indicated lines next to the pressure transducers. The lines were offset by $0.8 \% \mathrm{R}$. At the $93 \% \mathrm{R}$ station, the PSP over-predicts the suction peak at 
$\mathrm{x} / \mathrm{c}=0.04$ by 0.4 psia, or $3.3 \%$. In the range between an $\mathrm{x} / \mathrm{c}$ of $15 \%$ to $25 \%$ the PSP and transducer data agree within $2.4 \%$. At the $99 \% \mathrm{R}$ station the general shape of the PSP data matches the pressure transducers, but is biased low by an average of $7 \%$.

Biases in PSP are typically the result of the inherent temperature sensitivity of the PSP itself. The bias observed here implies that there is a temperature increase as blade radius increases. The TSP on the fourth blade was used to look for temperature gradients. These measurements are shown in Figure 10. The blade radius is in pixels since the TSP data were not mapped to a surface grid. The zero pixel location corresponds to roughly the $85 \% \mathrm{R}$ station and the 315 pixel location corresponds to the blade tip. The data have been normalized to show the surface temperature change as a function of radius from the $93 \% \mathrm{R}$ station - the inboard row of pressure transducers. These data clearly show an increase in surface temperature with increasing radial station. Between the $93 \%$ and $99 \%$ radial stations there was an approximately a $2.7^{\circ} \mathrm{F}$ increase in temperature.

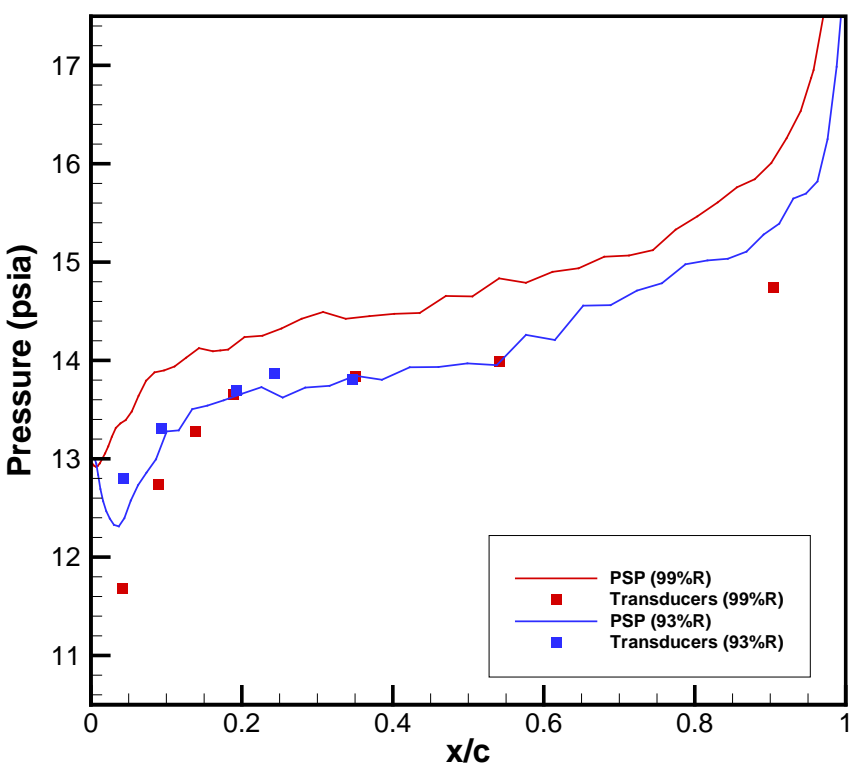

Fig. 9 - Blade surface pressures $-\mathrm{h} / \mathrm{D}=0.9, \mathrm{C}_{\mathrm{T}}=0.006$. Comparison between ensemble averaged blade pressure transducer and PSP extracted in a line (gradient symbols) next to the transducer line

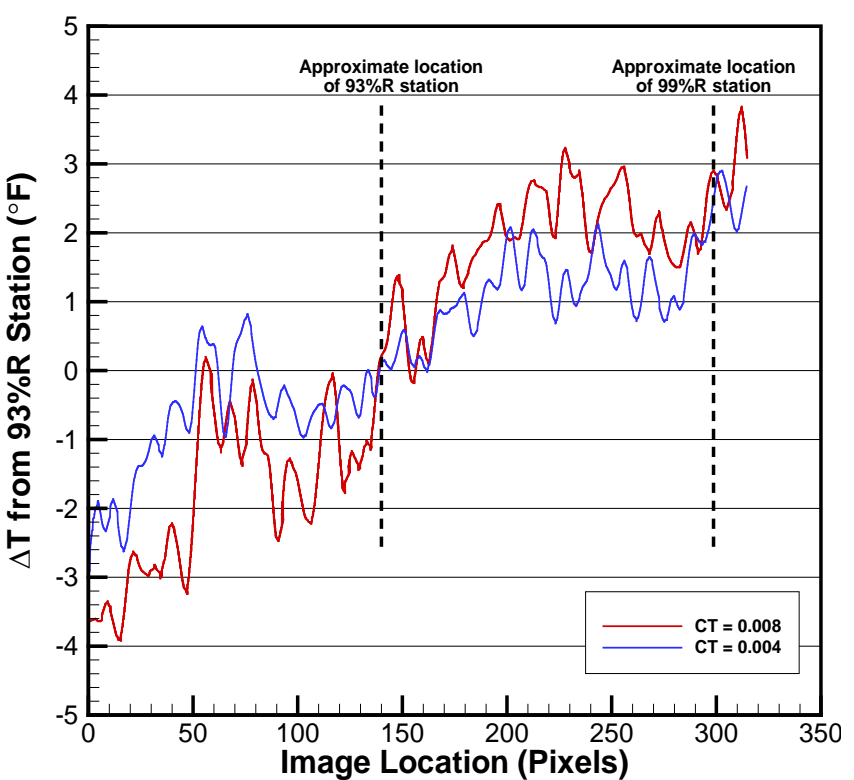

Fig. 10 -Blade surface temperature changes in hover

To account for the temperature increase between the two transducer rows, the a priori calibration with two different temperatures values was used: The first used the appropriate temperature for the $93 \% \mathrm{R}$ row and the second used a temperature approximately $2.7^{\circ} \mathrm{F}$ higher for the $99 \% \mathrm{R}$ row. The comparisons of these data with the transducers are shown in Figure 11. The temperature used with each a priori calibration is shown in the figure.

At a thrust coefficient of 0.004 , the PSP captures the behavior of the pressure transducers well. Agreement near the leading edge is worst. At the $99 \% \mathrm{R}$ location, the error is 0.8 psia or $4.6 \%$. At the $93 \% \mathrm{R}$ station the agreement is slightly better with an error of $3.9 \%$. Over the rest of the blade, the delta remains below $1 \%$ until the trailing edge, where it increases to $3.4 \%$. 


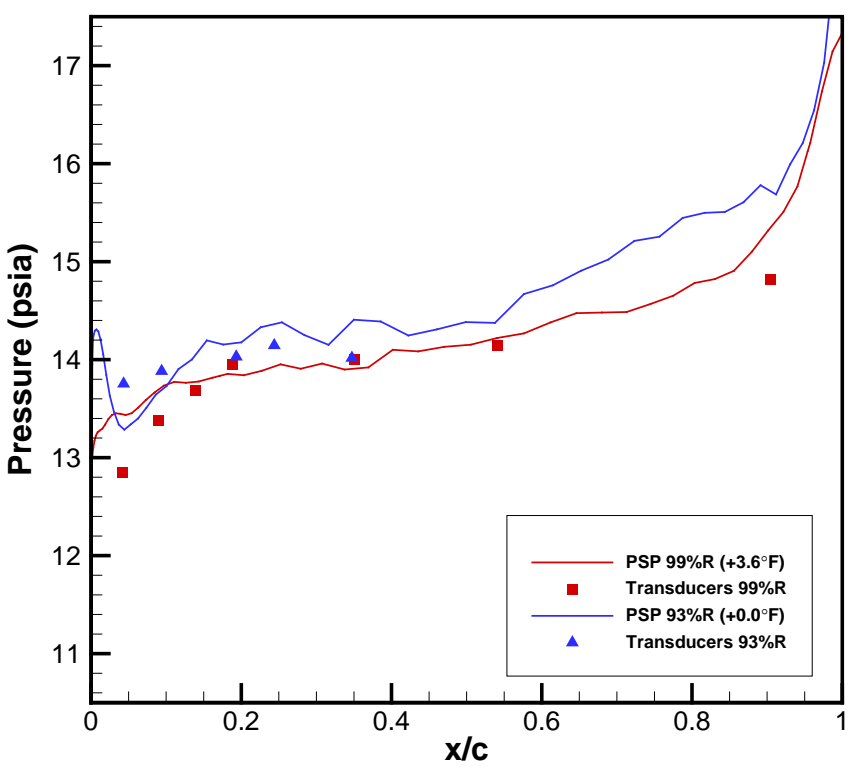

(a) $\mathrm{C}_{\mathrm{T}}=0.004$

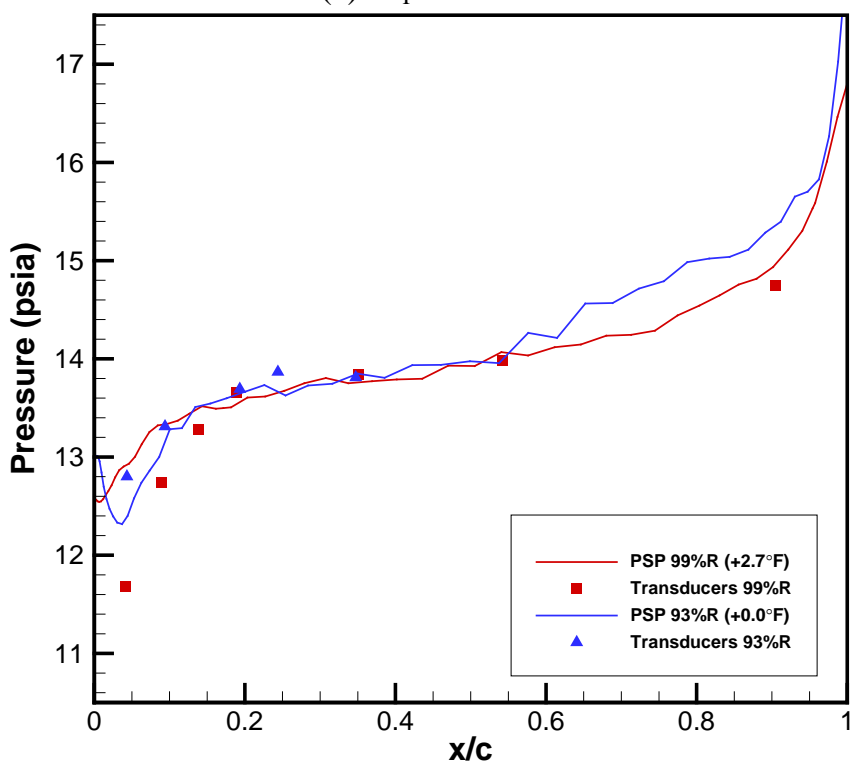

(b) $\mathrm{C}_{\mathrm{T}}=0.006$

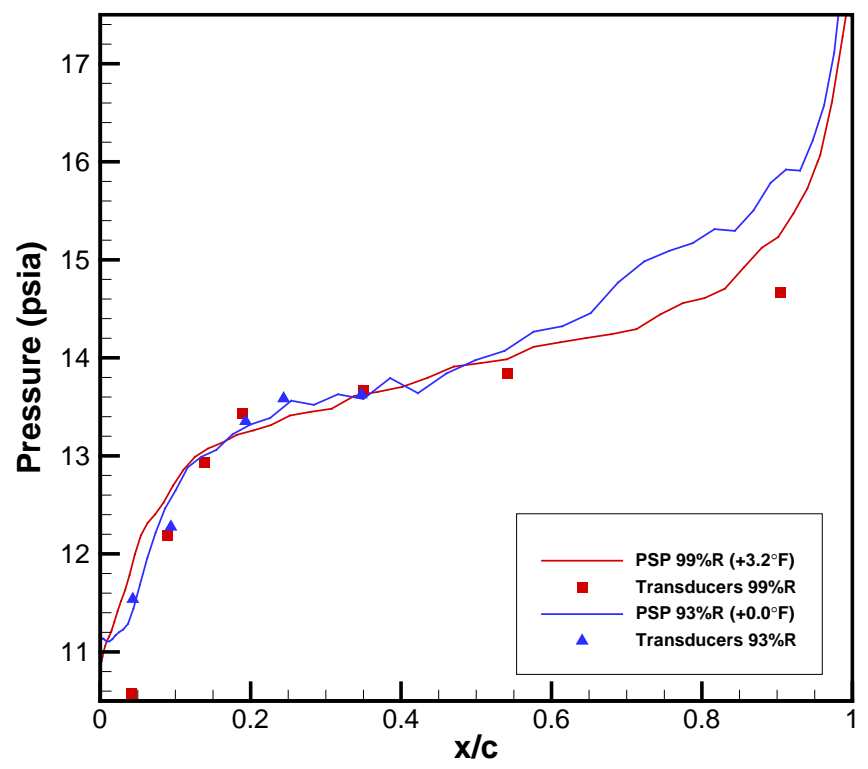

(c) $\mathrm{C}_{\mathrm{T}}=0.008$

Fig. 11 - Comparison between ensemble averaged blade pressure transducer and PSP data. PSP data compensated for radial temperature distribution.

At the higher thrust conditions, the agreement between the pressure transducers and PSP improves. The largest discrepancies also occur at the leading and trailing edges of the blade, with errors approaching $13.5 \%$ at the leading edge at the $99 \% \mathrm{R}$ station. At the $93 \% \mathrm{R}$ station the errors at the leading edge are lower with a maximum error of $3.6 \%$. Excluding the leading and trailing edge transducers, the average error for all remaining chordwise locations is approximately $1 \%$. The large discrepancies observed near the leading and trailing edges suggest that edge effects due to the blur in Gate 2 are responsible for the errors. The higher errors at the 99\%R support this, since larger motion is experienced with increasing radius.

PSP data from ten non-consecutive revolutions were averaged to examine the repeatability of the technique. Data from the $93 \%$ and $99 \%$ radial stations were extracted and averaged. They are presented in Figure 12. The shaded regions represent plus and minus one standard deviation. In general, the repeatability is very good. The largest differences are observed near the leading and trailing edges. The largest values noted near the leading edge are in the 0.4 to 0.5 psia range. Between an $\mathrm{x} / \mathrm{c}$ of 5 and $95 \%$, the average standard deviation varies between 0.07 and 0.14 psia for the two radial locations and all thrust conditions tested. These numbers correspond to standard deviations of 0.5 to $1.1 \%$ of the mean value. 


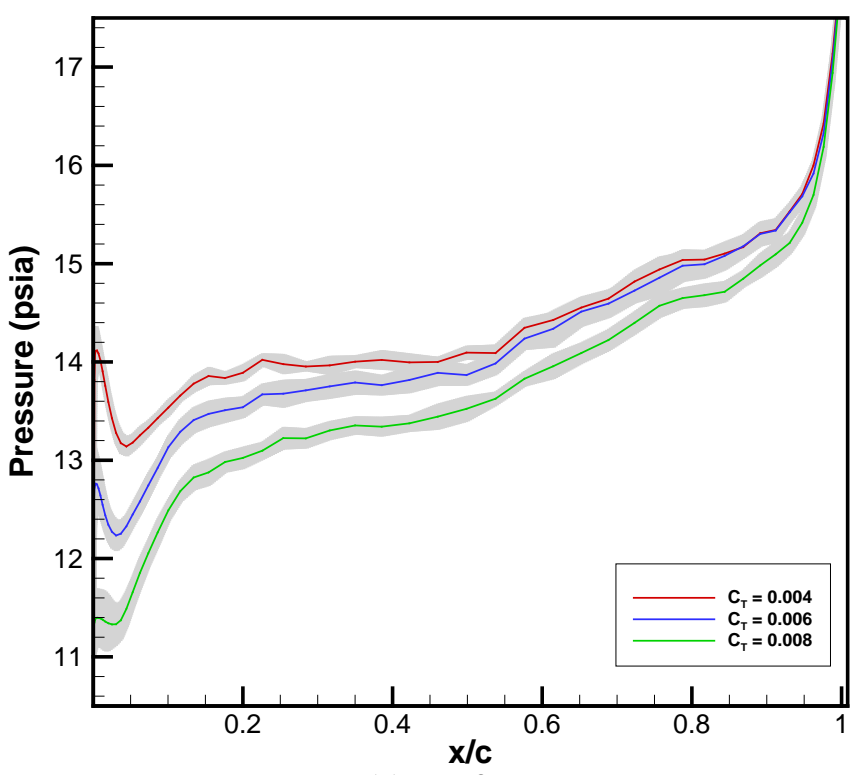

(a) $-93 \% \mathrm{R}$

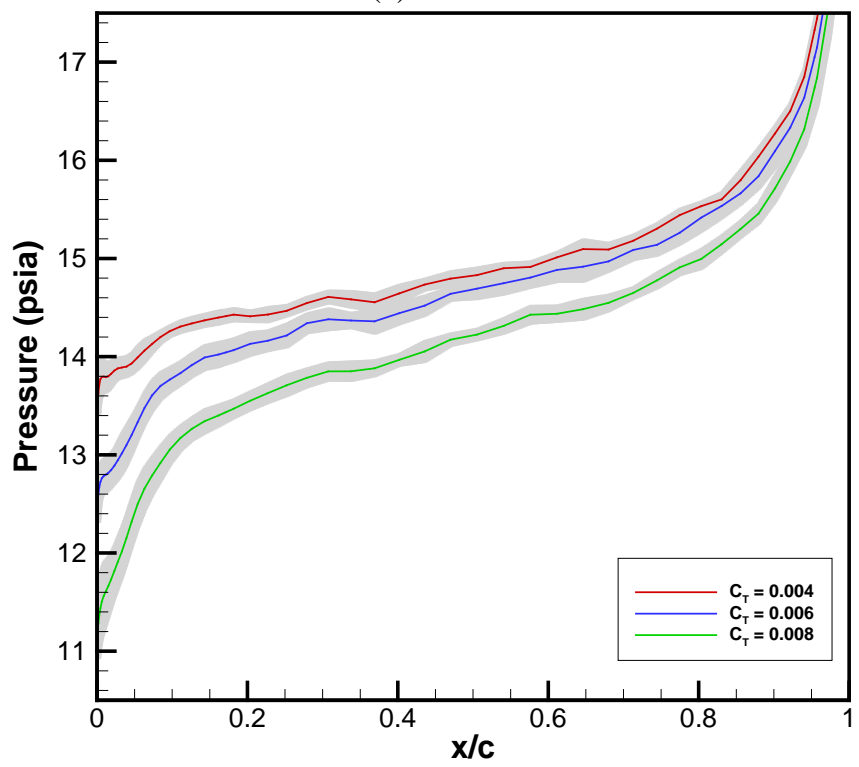

(b) $-99 \% \mathrm{R}$

Fig. 12 - Average PSP data from ten revolutions. Dotted lines are plus and minus one standard deviation.

\section{Forward Flight}

The PSP data from forward flight were measured at an advance ratio of 0.35 and $\alpha_{\text {Shaft }}=-6^{\circ}$. Four thrust conditions, $\mathrm{C}_{\mathrm{T}}=0.004,0.006,0.008$ and 0.010 , were examined at rotor azimuths of $101^{\circ}$ and $262^{\circ}$. In forward flight, only the $99 \% \mathrm{R}$ row of transducers were functional.

The surface pressure for all thrust coefficients on the advancing blade side (ABS) is shown in Figure 13. As was mentioned earlier, the method used to mask the pressure transducers during painting was changed for the forward flight test. The entire chordwise station was masked instead of using the tape dots. The resulting shape of the artifacts in the PSP data from the masking is now a line instead of a series of discrete dots. The PSP shows a narrow suction peak along the leading edge that grows radially as $\mathrm{C}_{\mathrm{T}}$ is increased. As one moves toward the trailing edge, there is a very broad low pressure region that slowly increases towards the trailing edge. Perhaps the most remarkable observation is the apparent lack of change in the pressure distribution given the wide range of thrust coefficients. Although at this blade azimuth, the suction peak may be stronger on the lower blade surface for rotor trim requirements. Local angle of attack may be zero or negative.

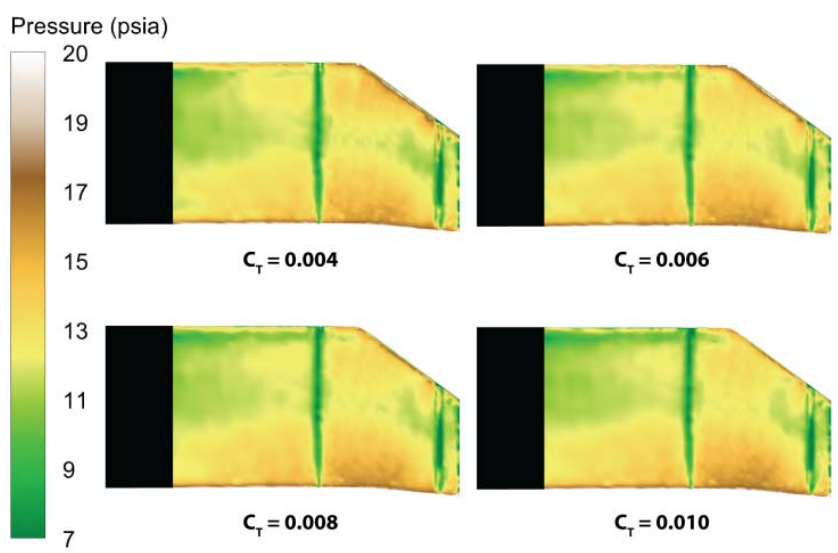

Fig. 13 - Wind tunnel blade tip upper surface pressure measurements, advancing blade side, $\mu=0.35, \psi=101^{\circ}$, $\mathrm{M}_{\text {Tip }, 101^{\circ}}=0.78$.

In order to provide insight on the lack of observed pressure distribution changes with changes in $C_{T}$, the ensemble averaged blade pitch during a revolution is shown in Figure 14. The blade pitch angles for the four thrust coefficients presented are shown in the plot. The azimuth of the PSP measurements are shown by the two dashed vertical lines. At $\psi=101^{\circ}$, the blade pitch for all of the cases is almost identical. Only $0.6^{\circ}$ separates the $\mathrm{C}_{\mathrm{T}}=0.004$ and $\mathrm{C}_{\mathrm{T}}$ $=0.010$ cases. Given these small changes in blade pitch, the nearly invariant pressure distributions are reasonable. 


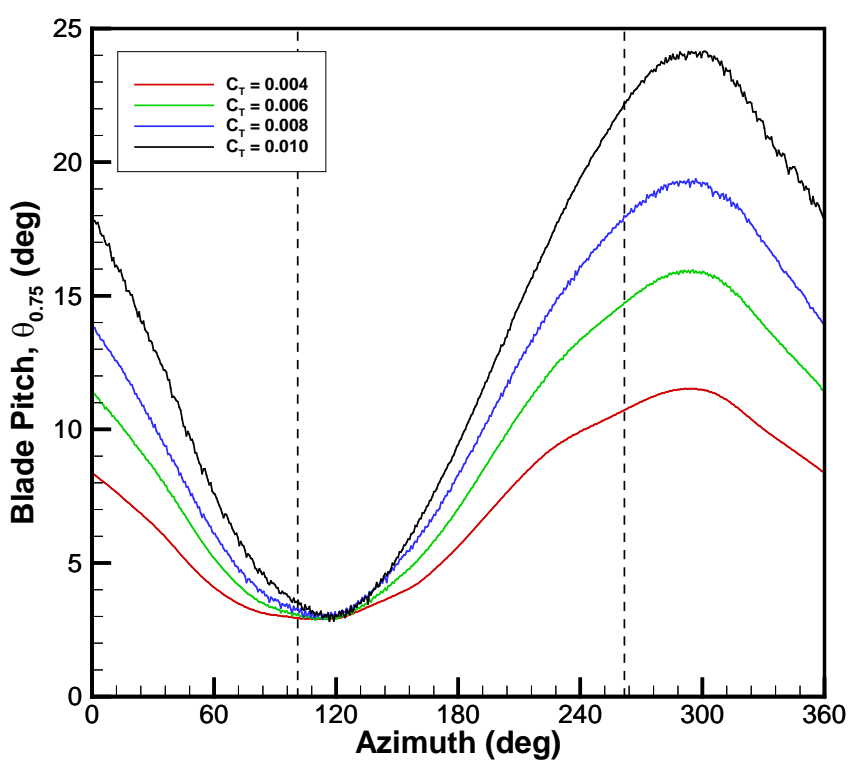

Fig. 14 -Blade pitch during one revolution. The dashed lines are the azimuths were PSP data was collected

On the retreating blade side (RBS), there is an $11.5^{\circ}$ difference between the two ends of the thrust sweep. In all cases, the most prominent feature is the suction peak (Figure 15). As thrust coefficient increases, the length and strength of the suction peak also increases. At the lowest $\mathrm{C}_{\mathrm{T}}$, the peak is barely visible and extends radially outboard to approximately the $93 \% \mathrm{R}$ station. The peak extends to $95 \% \mathrm{R}$ at a $\mathrm{C}_{\mathrm{T}}$ of 0.006 and then extends to approximately the 98\%R station for the two highest thrust conditions. The tip vortex is visible as the slanted low pressure region near the tip. It begins to become visible at a $\mathrm{C}_{\mathrm{T}}=0.006$ and is clearly visible at the two highest thrust coefficients. It should be noted that tip vortex that is seen in the PSP at the tip does not appear in the tap data. From visual inspection of the PSP data, it seems that the phenomenon flows just past the last pressure tap, or possibly between two transducers. This shows one of the greatest advantages to using PSP: the ability to visualize and measure global pressure distributions, as opposed to localized pressure measurements acquired from pressure transducers.

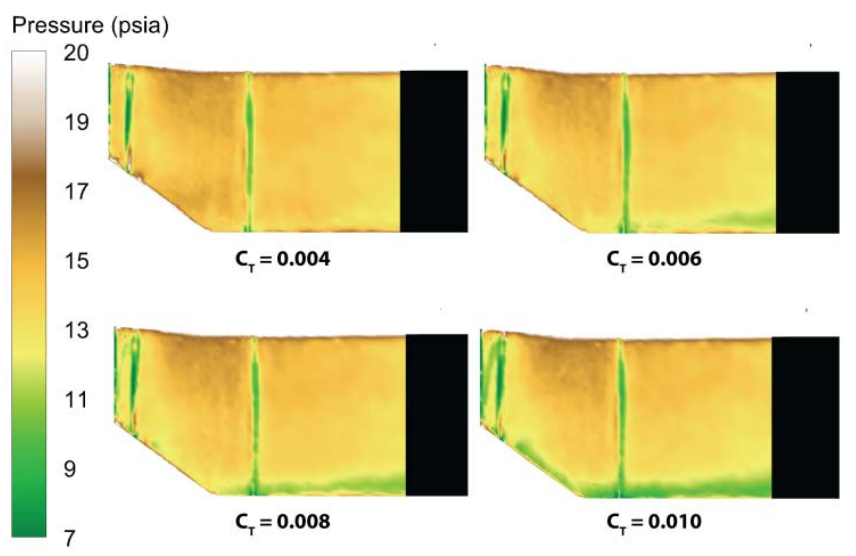

Fig. 15 - Wind tunnel blade tip upper surface pressure measurements, retreating blade side, $\mu=0.35, \psi=262^{\circ}$, $\mathrm{M}_{\text {Tip, 262 }}=0.38$.

One feature of note in both the advancing and retreating blade sides PSP data is a circular high pressure region at the leading edge, inboard of the $99 \% \mathrm{R}$ transducer row. The indicated pressure of the region changes with thrust condition indicating that the paint in that region is responding to pressure changes. It should also be noted that the size changes with $\mathrm{C}_{\mathrm{T}}$. This location corresponds to one of the blotches that were patched in the wind-off image. At this point, however, it is not clear if the elevated pressure is due to aerodynamics (e.g. a surface defect), an inhomogeneity in the paint resulting from application process, the wind-off patching, or a combination of all three. Unfortunately, this is the radial location where the PSP is sampled for comparison to the pressure transducers. Since the flow at the tip is highly three-dimensional, the PSP needs to be sampled as close as reasonably possible to the transducer orifices, which precludes relocating the sampling station to another radial location. As a result of this constraint, this region has a large influence in the PSP, pressure transducer comparisons near the leading edge.

The pressure transducer measurements for the ABS at the $99 \% \mathrm{R}$ station for the four thrust conditions are shown as the square symbols in Figure 16. Lines representing the PSP data extracted from the $98.2 \% \mathrm{R}$ are superimposed. All four thrust conditions behave in a similar manner. The PSP significantly overpredicts the pressure from the leading edge to an $\mathrm{x} / \mathrm{c}$ of 0.20 , which overlaps with the high pressure region discussed in the previous paragraph. From $\mathrm{x} / \mathrm{c}=0.20$ to 0.35 the PSP agrees well with the transducers. The discrepancy ranges from 0.05 to 0.68 psia or 0.4 to $5.6 \%$. After that location, the PSP starts to underpredict the transducers and then gradually agrees with the transducer at $\mathrm{x} / \mathrm{c}=0.95$. The maximum difference over that chordwise range is about 1.3 psia or $9.4 \%$. 


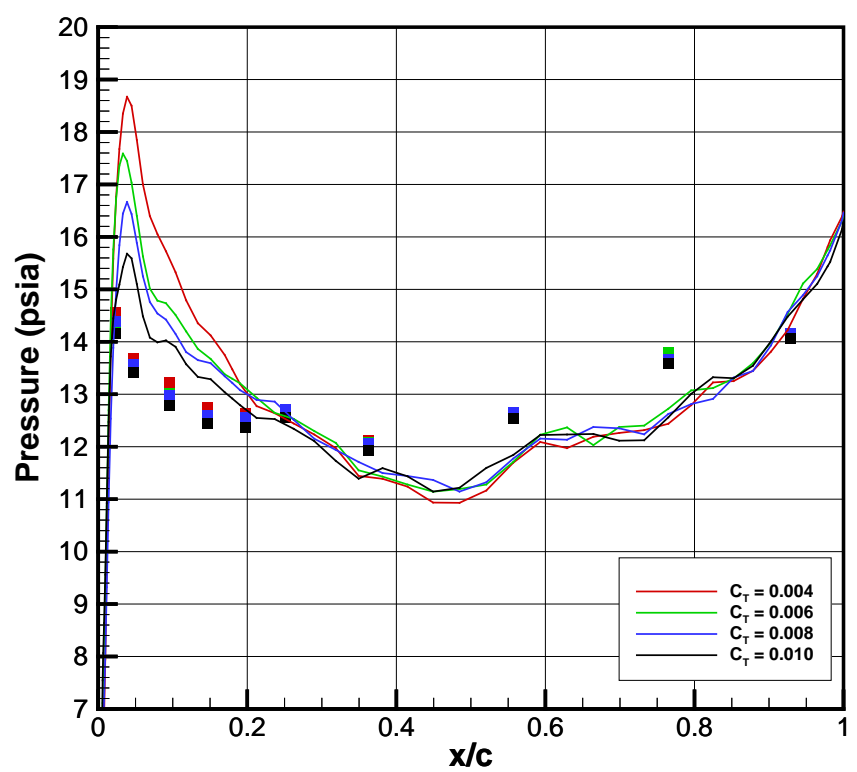

Fig. 16 - Comparison between pressure transducers (squares) and PSP on the ABS. The pressure transducers, square symbols, are at the $99 \% \mathrm{R}$ station. PSP is sampled at the $98.2 \% \mathrm{R}$ station.

For the RBS, the comparison is shown in Figure 17. All thrust conditions show the high pressure region near the leading edge. By an $\mathrm{x} / \mathrm{c}$ of $15 \%$, the three highest thrust conditions match the transducer data (within 0.6\%). The $\mathrm{C}_{\mathrm{T}}$ $=0.004$ case does not show reasonable agreement until the $20 \%$ of the chord ( 0.51 psia or $3.7 \%$ difference). The comparison for all thrust cases is very good to $\mathrm{x} / \mathrm{c}=0.75$. At the $95 \%$ chordwise station the agreement is still reasonable, but immediately aft of chordwise edge effects cause a sudden apparent increase in the PSP data.

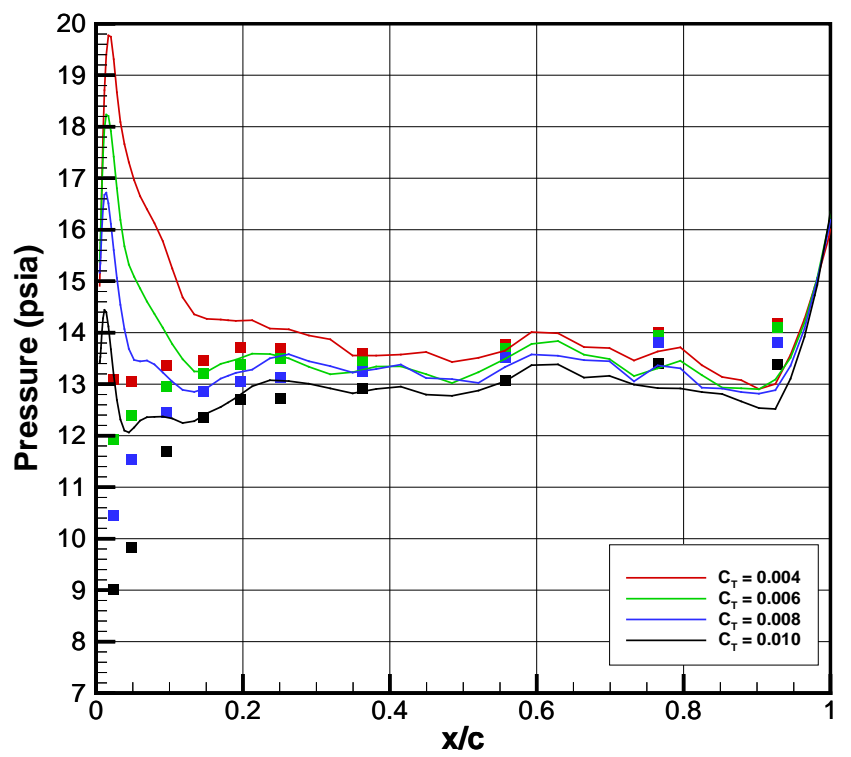

Fig. 17 - Comparison between pressure transducers (squares) and PSP on the RBS.

\section{CONCLUDING REMARKS}

This paper discusses the application of PSP using laserbased excitation for measurement of the upper surface pressure distributions on the tips of rotor blades in both hover and simulated forward flight. The testing was conducted in the Rotor Test Cell and the 14- by 22-Foot Subsonic Tunnel at the NASA Langley Research Center on the GRMS test stand. The rotor for this test was a dynamic pressure instrumented rotor with an $11 \mathrm{ft} 1 \mathrm{in}$. diameter, 5.45 in. main chord and a swept, tapered tip. Three thrust conditions were examined in hover, $\mathrm{C}_{\mathrm{T}}=0.004,0.006$ and 0.008. In forward flight, $\mathrm{C}_{\mathrm{T}}=0.010$, was added to the thrust sweep. All forward flight testing was conducted at $\mu=0.35$.

Compared to previous hover PSP work on rotor blades using LED arrays for excitation, the laser-based excitation provided superior luminophore excitation, enabling single shot data acquisition. This removes the smearing of the pressure distribution that results from building the images from hundreds of exposures when using the LED method. Using the laser-based method relies on an interline transfer CCD camera which functionally results in the length of the Gate 2 image being fixed by the lifetime of the luminophore. At the rotor speed for this test, the blade moves 0.080 in. at the tip during the $10 \mu$ s luminophore decay. The blur caused by this motion is enough to result in edge effects that manifest themselves as non-physical pressures. The edge effects are worst on the leading and trailing edges of the blade.

In hover, the pressure distributions clearly show the development of the suction peak and the gradual pressure increase towards the trailing edge of the blade. The tip vortex is also visible. The vortex footprint begins to become visible at a $\mathrm{C}_{\mathrm{T}}=0.006$ and is clearly visible by a $\mathrm{C}_{\mathrm{T}}=0.008$. In forward flight, on the advancing blade side, the pressure distributions show very little change at the four thrust conditions examined. This is the result of very small differences in blade pitch angle at $\psi=101^{\circ}$. On the retreating blade side, the pitch angle changes are much larger and result in clear changes between the thrust conditions as well as a distinct tip vortex that is captured by the PSP, but not indicated in the pressure transducer measurements.

The visualization of the tip vortex illustrates one of the biggest advantages to using PSP: the ability to visualize and measure global pressure distributions, as opposed to localized pressure measurements acquired from pressure transducers. Furthermore, since this technique can resolve the azimuthally varying blade tip pressure distribution, including the tip vortex, it may enable a better understanding of rotor blade tip aerodynamics. 
When the PSP is compared to pressure transducer data, the PSP shows a bias in the radial direction that is the result of temperature gradient on the blade. TSP measurements conducted on the fourth blade indicate that there is approximately a $2.7^{\circ} \mathrm{F}$ increase between the $93 \% \mathrm{R}$ and 99\%R row transducers. In hover, when the PSP is corrected for the temperature gradient, comparison with the pressure taps is very good. The largest discrepancies occur at the leading and trailing edges. It is hypothesized that these discrepancies are the result of the blade motion in Gate 2.

In forward flight the comparison between PSP and transducers shows that the correlation is good from the quarter chord to an $\mathrm{x} / \mathrm{c}=0.95$. Aft of that station, the edge effects are clearly visible. The poor correlation forward of the quarter chord is due to a circular high pressure region on the leading edge in the PSP. At this point, however, it is not clear if the elevated pressure is due to aerodynamics (e.g. a surface defect), an inhomogeneity in the paint resulting from the application process, the wind-off patching, or a combination of all three.

The laser-based PSP measurements described in this paper show that PSP has the potential to provide accurate, high spatial resolution, azimuth-resolved pressure data on rotor blade tips. Based on the experience gained during these tests, however, the following recommendations are suggested to improve the technique.

1. Modify the luminophore doping/wind-off image pair acquisition process in order to obtain “clean” images, enabling PSP application inhomogenaity correction.

2. Modify the data reduction process to incorporate TSP surface temperature measurements, enabling correction for blade temperature gradients.

3. Develop a technique for Gate 2 blur reduction to remove edge effects. Work in this area has already started (ref. 21).

\section{ACKNOWLEDGEMENTS}

The authors would like to acknowledge the technical staff at the 14- by 22-Foot Subsonic Tunnel for their tireless assistance in the preparation and execution of the hover and forward flight tests. Their support of seven day a week tunnel operations is greatly appreciated, without which the forward flight test would not have occurred. In addition, the authors would like to thank Josh G. Ballard, Andrew Harrison, W. Derry Mace, Bryan C. Mann, and Stephen A. "Fred" Mason for always going above and beyond the call of duty; Wayne R. Mantay for the hours of discussion that lead to this work; and Susan A. Gorton for her support and advocacy.

\section{REFERENCES}

${ }^{1}$ McAlister, K.W. and Heineck, J.T., "Measurements of the Early Development of Trailing Vorticity from a Rotor," NASA TP-2002-211848, 2002.

${ }^{2}$ van der Wall, B.G., Burley, C.L., Yu, Y., Richard, H., Pengel, K. and Beaumier, P., The HART II test measurement of helicopter rotor wakes, Aerospace Science and Technology, Volume 8, Issue 4, June 2004, Pages 273284.

${ }^{3}$ Bosnyakov, S., Bykov, A., and Coulech, V., "Blade deformation and PSP measurements on the large scale rotor by video metric system," ICIASF '97 - International Congress on Instrumentation in Aerospace Simulation Facilities, 17th, Pacific Grove, CA, Sept. 29-Oct. 2, 1997, Record (A98-18712 03-35), Piscataway, NJ, Institute of Electrical and Electronics Engineers, Inc., 1997, p. 95-104, Piscataway, NJ: Institute of Electrical and Electronics Engineers, Inc., 1997, pp. 95.

${ }^{4}$ Koulesh, V.P., Mosharov, V.E., and Radchenko, V.N., Improvement of Fast Binary Pressure-Sensitive Paint Technology for Helicopter Rotor Blade Investigations, Vol. AD-A395378; ARO-39806.1-EG, 2000.

${ }^{5}$ Watkins, A.N., Jordan, J.D., Leighty, B.D., Ingram, J.L. and Oglesby, D.M., "Development of Next Generation Lifetime PSP Imaging Systems," Proc. 20th Int. Congr. Instrumentation in Aerospace Facilities, Gottingen, Germany, 2003, pp. 372-382.

${ }^{6}$ Wong, O.D., Watkins, A.N., and Ingram, J.L., "Pressure Sensitive Paint Measurements on 15\% Scale Rotor Blades in Hover”, presented at the 35th AIAA Fluid Dynamics Conference and Exhibit, Toronto, Ontario, Canada, June 69, 2005, Paper 2005-5008.

${ }^{7}$ Wong, O.D., Noonan, K.W., Watkins, A.N., Jenkins, L.N., and Yao, C.S., "Non-Intrusive Measurements of a FourBladed Rotor in Hover - A First Look", Presented at the American Helicopter Society Aeromechanics Specialists' Conference, San Francisco, CA, January 20-22, 2010.

${ }^{8}$ Murrill, R.J, "Operation and Maintenance Manual for the General Rotor Model System”, SER-50986, NAS1-12674, May 1977.

${ }^{9}$ Freeman, C.E. and Mineck, R.E., "Fuselage Surface Pressure Measurements of a Helicopter Wind-Tunnel Model with a 3.15-meter Diameter Single Main Rotor”, NASA TM- 80051, 1979.

${ }^{10}$ Schaeffler, N.W., Allan, B.G., Lienard, C., Le Pape, A.” Progress Towards Fuselage Drag Reduction via Active Flow Control: A Combined CFD and Experimental Effort”, 36th European Rotorcraft Forum, Paris, France, Sept 7-9, 2010.

${ }^{11}$ Noonan, K.W., “Aerodynamic characteristics of two rotorcraft airfoils designed for application to the inboard region of a main rotor blade”, NASA-TP-3009, AVSCOMTR-90-B-005, 1990.

${ }^{12}$ Noonan, K.W., "Aerodynamic characteristics of a rotorcraft airfoil designed for the tip region of a main rotor blade”, NASA-TM-4264, AVSCOM-TR-91-B-003, 1991. 
${ }^{13}$ Gentry, G.L., Quinto, P.F., Gatlin, G.M., and Applin, Z.T., "The Langley 14- by 22-Foot Subsonic Tunnel: Description, Flow Characteristics and Guide for Users”, NASA TP-3008, 1990.

${ }^{14}$ Fleming, G. A., "RASP: Rotor Azimuth Synchronization Program (RASP) User's Guide, Version 1.3,” NASA Langley Research Center, February 6, 2008.

${ }^{15}$ Scroggin, A.M., Processing and Optimization of Doped Polymer/Ceramic Composite Films for LuminescenceBased Pressure and Temperature Measurement in Aerodynamic Applications, MS Thesis, School of Material Science and Engineering, Purdue University, 1999.

${ }^{16}$ Scroggin, A.M., Slamovich, E.B., Crafton, J.W., Lachendro, N., and Sullivan, J.P., "Porous Polymer/Ceramic Composites for Luminescence-Based Temperature and Pressure Measurement," Materials Research Society Symposium Proceedings, Vol. 560, pp. 357-352.

${ }^{17}$ Liu, T., and Sullivan, J., Pressure and Temperature Sensitive Paints (Experimental Fluid Dynamics), SpringerVerlag, Berlin, 2004, p. 318.

${ }^{18}$ Gregory, J.W., Asai, K., Kameda, M., Liu, T., and Sullivan, J.P., "A Review of Pressure-Sensitive Paint for High-Speed and Unsteady Aerodynamics," Proceedings of the Institution of Mechanical Engineers - Part G: Journal of Aerospace Engineering, Vol. 222, No. 2, 2008, pp. 249290, doi: 10.1243/09544100JAERO243.

${ }^{19}$ Bell, J.H., "Accuracy Limitations of Lifetime-Based Pressure-Sensitive Paint (PSP) Measurements," 19th International Congress on Instrumentation in Aerospace Simulation Facilities, IEEE, Cleveland, OH, 2001, pp. 516.

${ }^{20}$ Ruyten, W. and Sellers, M., "Lifetime Analysis of the Pressure-Sensitive Paint PtTFPP in FIB," 42nd Aerospace Sciences Meeting, AIAA, Reno, NV, 2004, Paper 2004881.

${ }^{21}$ Juliano, T.J., Disotell, K.J., Gregory, J.W., Crafton, J., Fonov, S., "Motion-Deblurred, Fast-Response PressureSensitive Paint on a Rotor in Forward Flight", Measurement Science \& Technology, Vol. 23, No. 4, 2012, p. 04503, doi: 10.1088/0957-0233/23/4/045303. 